MedieKultur | Journal of media and communication research | ISSN 1901-9726

Article - Theme section

\title{
Bluetooth orgasms
}

\section{Marilia Kaisar}

MedieKultur 2021, 71, 143-160

Published by SMID | Society of Media researchers In Denmark | www.smid.dk The online version of this text can be found open access at www.mediekultur.dk

\begin{abstract}
Bluetooth-operated sex toys penetrate and are penetrated by the human body, leaving code behind. This article analyzes the relationships that develop between bodies and Bluetooth-operated interactive sex toys. Resembling the pods and portals of David Cronenberg's film eXistenZ, interactive sex toys allow us to consider how technologies relate intimately to the sexual body. I use Massumi's work on virtuality and affect theory as a starting point from which to frame embodiment, virtuality, and the circulation of affects. Further, I consider the importance of embodiment and the translations of intensities and vibrations through digital coding among the open sexual body, the technology of the sexual machine, and the applications that foster those connections, in the context of Bluetooth-operated sex toys. This article advocates the need to consider intimate encounters between interactive sex toys and bodies as complex technological and biological assemblages, where vibrating machines and the human body's flesh come into intimate connection through datafication.
\end{abstract}

\section{Keywords}

Bluetooth sex toys, virtual, affect, body, sexuality 


\section{Introduction: From bioports and pods to interactive vibrations}

David Cronenberg's film eXistenZ (1999) presents the human body as an interface that can be penetrated by bioelectronic devices; bioports and pods allow the protagonists to immerse themselves in a virtual reality game. The bioport, resembling a contemporary USB port, serves as an orifice as well as an erogenous zone. When a pod is inserted into the body, the user is transported into the virtual world of the game. Bioports can be easily attained, like getting a piercing at the mall. In her essay "Becoming Inorganic: Cronenberg's eXistenZ, Virtuality, and the Death Drive", de Lauretis reads eXistenZ as a metaphor for creative destruction and schizophrenia in postmodernity, using Freud's theory of the drives. The bioports seamlessly penetrate and blend with the human body - they are organic technologies that are neither human nor animal.

In a reversal of the old body economy, the bioport is a receptacle for the pod: a genetically engineered external sexual organ that, when inserted directly into the body, serves as a penis, and when ported into through the UmbyCord, becomes a uterus or vagina. Surely, in a world in which anyone can easily acquire a bioport-legally as "industry standard" or illegally, if necessary, with a quick stop at the gas station-anatomy is no longer destiny (de Lauretis, 2008, p. 106). Technology in eXistenZ is fleshy and soft, full of fluids, sounds, and blood-like bodily organs - as well as sexual and deadly. Within the virtual game, the bioport and game stick amplify the sexual experience while defying notions of gender and reality.

In eXistenZ, there is a separation between humans and technologies, but when united, they lead to the world of the virtual reality game. In the film, de Lauretis demonstrates that "the sexual drive does not originate in the physical body as such but in the psychic structure of fantasy, and hence it is only through fantasy that desire is sustained" (de Lauretis, 2008, p. 107). She writes:

In fact, as becomes apparent in the sex scene between the two leads, the bioport has taken over the erogenous function of both anus and vagina, of which it is not a metaphor but a replacement, signaling a new sexual economy of the human body. (de Lauretis, 2008, p. 101)

Thirty years after the film's release, I want to consider Cronenberg's representations of pods and portals as metaphors for interactive Bluetooth-operated sex toys for couples who are apart. Despite the prominence of virtual-reality headsets in the escapist advertisements for the interactive sex toys I examine here, I am trying to define the term virtuality as something separate from the congested notion of virtual reality. The promise of sex across distances is virtual - a field full of potential - but through the aid of digital technologies, as waves and affects move from the app to the toy to the human body, new sexual realities are embodied and datafied. What I argue is that, as in Cronenberg's film eXistenZ, sexual desire and virtual sex belong to the imagination and become a concrete experience through the sexual assemblages of bodies and machines. In eXistenZ, the 
bioport operates as an orifice in the body that allows the user to transcend the actual into the virtual, but contemporary Bluetooth-enhanced interactive sex toys operate quite differently.

Marketed toward heterosexual couples in long-distance relationships or as a useful tool for webcam models masturbating in front of their web cameras, interactive sex toys function with the aid of a smartphone application in two ways-either with one user controlling a toy being used by another or as a paired set of toys-a masturbator (stroker) and a vibrator, two vibrators, or two strokers. The paired devices mirror each other's movements. For example, the strokes of the person using a masturbator are reflected in the vibrations of the egg/bullet/rabbit/anal plug or dildo. This relationship between the two toys is mediated via a Bluetooth wireless smartphone connection and through a smartphone application that allows the two toys to communicate so that the two partners can have a shared experience. This relationship creates a site of contact among the fleshy human body, the sex toys, and the cloud.

Using the body as a nexus point and embodiment in a specific space and time as the point of entry, this article explores the relationships among vibrating dildos, strokers, affects, applications, and human bodies. The virtual materializes through specific humandesigned objects that carry in their code and functions the societies that structured them. How does the sexual body relate to technology? How does the potentiality of virtual sex and desire carry us into sexual assemblages of human and non-human organs? Bluetooth-controlled vibrating sex toys operated through smartphone applications embedded in platform societies allow us to consider the dualisms of nature/technology, body/machine, and real/virtual and explore the intensive qualities that evolve in sexual synergies between bodies and machines.

To examine those relationships, I will first attempt to define affect and virtuality through affect theory. After exploring in depth how those sexual machines operate as biotechnologies that relate intimately to the sexual body, I discuss the importance of Bluetooth technologies and applications that allow interactive sex toys to function without wires. The applications necessary for interactive sexual encounters render the human body "leaky", extracting data from those intimate moments between human and non-human sexual organs. Finally, using the work of Preciado (2018), I consider their potential to create a new form of sex and decentralize norms of gender and sexuality. Bluetooth-operated sex toys can be conceptualized as sexual organs or machines that engage intimately with the human body and are designed in a way that reflects ideologies and produces subjectivity formations.

\section{Affect, the virtual, and the body}

The body is more than simply a tool for experiencing the world; it is also a reflector of emotion, feeling, and affect, sometimes experiencing before verbalizing. Body and mind 
can be perceived as an interconnected entity shaped by the environment. The brain, the body, and the world become a reciprocal loop that continuously receives and sends signals. For Pellegrini and Puar (2009), affect can be conceived of as a set of psychological processes that cannot be perceived through language and cognition alone but also affect the body. For them, affect is "precisely what allows the body to be an open system, always in concert with its virtuality, the potential of becoming" (Pellegrini \& Puar, 2009, p. 37). In a similar vein, in The Cultural Politics of Emotion, Ahmed (2014, p. 1) explores "how emotions work to shape the 'surfaces' of individual and collective bodies", although she sees how "bodies take the shape of every contact they have with objects and others" (Ahmed, 2014, p. 1). In a similar manner, as the sexual body encounters a sex toy-whether interactive or not-both the body and the object are shaped by this interaction. The body opens and becomes a vulnerable recipient and sender of vibrations that travel through digital networks via the platform across continents.

Interactive sex toy technology uses the online application as an interface that allows affects to travel among bodies, sexual machines, smartphones, and computers across distances. Bluetooth-connected sex toys vibrate as they allow affects (i.e., orgasms, vibrations, strokes, intimacy, desire) to travel from one device to the next, from one body to another. The promise of virtual sex is experienced in an embodied manner through both body and mind, as the waves of the intensities are registered and recorded as data within the applications that allow them to operate. This datafied affective exchange actively alters the shape of the interactive sex toys and the waves they transmit, which are then improved to match the data tracked by the consumers and their bodies.

In Parables of the Virtual, Massumi explores tropes of virtuality, with a focus on the body and affect. He begins by framing the body as a site of experience, describing how "it moves as it feels, and it feels itself moving" (Massumi, 2002, p. 1). The body is not concrete but rather in constant movement and passage through various states and intensities that are felt and perceived. In this sense, the body can both affect and be affected. Massumi defines affect as "intensity" and explores how it differs from emotion. For him, emotion is affect that has entered the realm of language-subjective content, a qualified intensity that has managed to enter function and meaning (Massumi, 2002, p. 28). The experience of intensity cannot yet be verbalized. He writes that "the body absorbs impulses and vibrations quicker than it can perceive them" (Massumi, 2002, p. 29). The mind is a perception center that puts thought into code and language. The body experiences the same intensities but expresses those events in a realm that is different from but parallel to the mind. Bluetooth sex toys and the vibrations they mediate are experienced as unregistered intensities in the body, made possible through code and acting as transducers carrying affects between bodies and machines across the world.

What is being termed affect in this article is intensities that escape linguistic description-it is what can be experienced but not accurately defined. Even when affect is verbalized, some element of vibratory matter escapes. Even when we try to capture and 
captivate affect, as through the perception of emotions, some of its elements escape, remaining unactualized. I want to borrow from Massumi the notions of the virtual and affect and their relationship to embodiment. The virtual enacts pressures upon and immediately relates to the body. Even if those intensities are invisible, their potentiality translates into the field of actuality and the real.

In popular culture, the virtual is defined as something that exists or is simulated on a computer. Since its conception, the virtual has been a loaded term, one with many meanings that have changed over time. In The Virtual, Shields traces the meaning of the virtual as a concept and attempts to contrast it with the concrete, instead of the actual, exploring how, in the contemporary moment, the virtual is materialized through what he defines as "digital virtualities" (Shields, 2002, p. xvi). Shields defines virtual worlds as simulations that initially reproduce actual worlds and real bodies, but then take on a life of their own. For him, the everyday notion of virtual can be conveyed in the sentence "What is so in essence but not in form" (Shields, 2002, p. 22).

There appear to be two main definitions of the virtual: one that connects it with that which is unseen, a mental space of potentiality; and one in which it is equivalent to the digital. Massumi sees a clear distinction between what he calls the virtual and digital technologies: The virtual is inaccessible to the senses and can only be felt in its effects (a concept diametrically opposed to Shields's), and digital technologies offer a weak connection to the virtual and always require analogue processes to be experienced and transduced in effect. He writes:

In sensation the thinking-feeling-body is operating as a transducer. If sensation is the analogue processing by body-matter of ongoing transformative forces, then foremost among them are forces of appearing as such: coming into being, registering as becoming. The body, sensor of change, is transducer of the virtual. (Massumi, 2002, p. 135).

In this article, the virtual is defined as something between the definitions of Shields and Massumi, something that has engulfed within it the Deleuzian notion of potentiality, but that can be experienced and mediated through contemporary digital technologies. If what those sex toys allow to occur is a form of virtual sex or cybersex, then coding and digitalization is the mode that allows vibrations and affects to travel from one toy to the next and be experienced in the body. There is a process of constant translation and datafication as the vibrations travel from the orgasming body to the sex toy, to the smartphone application via Bluetooth, to the partner's smartphone application miles away, back to the sex toy, and finally back to another body. What is virtual, "in essence but not in form", is the potential of a sexual encounter that defies distances. What is a concrete reality is also a travel of affect between human and non-human sexual organs and a simulated act of mutual masturbation that is allowed through technological extensions and communication technologies. 
This philosophical and ethical questions of sex using interactive sex toys and communication technologies has been further explored by Sparrow and Karas (2020), who discuss cases of rape by deception enabled by teledildonics. They recreate several scenarios in which, through the use of teledildonics, users can be deceived and sexually assaulted, focusing on whether those sexual assaults by deception can be defined as rape (Sparrow \& Karas, 2020, p. 176). They discuss whether the use of interactive sex toys would constitute sex or mutual masturbation and how, thus, only in the case of penetrative use of the toys would malicious deception result in a legal case of rape by deception. Since the sex toy can be inserted and removed from the body by the main user and not by the remote controller, Sparrow and Karas (2020) conclude that interactive sex toys result in simulated mutual masturbation rather than sexual or coital intercourse. Thus, when sex toys are taken over by hackers, or when users are deceived about the partner with whom they are having sexual interactions, this is more likely defined as sexual assault and can only be rape if there is penetration involved. Incidents like this and theorization of this sort demonstrates where holes and dangers appear in society's definition of, for example, sexual intercourse, sexual assault, and rape. Multiple non-human agents entering the sexual experience complicate and confuse the definitions that society has created thus far for sexual interactions.

\section{Teledildonics: Strokers and vibrators}

Bluetooth sex toys are manufactured by various companies, but for the purposes of this article, I considered the products from the companies We-Vibe, KIIROO, and Lovense. All these toys can either function independently as individual toys or be moderated from a distance when they are connected via Bluetooth to the user's smartphone application. The user who holds a specific sex toy can then be paired through the application with anyone across the world who has also downloaded the application to their smartphone by sending them an invitation. The other user can also connect his or her own Bluetooth sex toys to the app. They can then remotely operate each other's sex toys from a distance or use their paired sex toys together.

What I call "Bluetooth sex toys" in this article are known by many names, but the most popular term is teledildonics (Liberati, 2017). The names of the toys vary by company, but they are based on the same idea: KIIROO calls their couple products "interactive sex toys", We-Vibe calls them "app-enabled vibrators", and Lovense calls them "interactive sex toys" or "long-distance sex toys". The wide range of names is reflected in the relevant scholarly bibliography under the terms "Wi-Fi-enabled vibrators" (Wilson-Barnao \& Collie, 2018) and "Internet-enabled haptic sex toys" (IEHST) (Sparrow \& Karas, 2020).

The term teledildonics is not entirely new. In Virtual Reality, Rheingold defines teledildonics as a communication device, not a sex machine, that allows people to have sexual experiences with other people at a distance (Rheingold, 1992, p. 345). For Rhein- 
gold, teledildonics will evolve as a conjunction of virtual reality and telecommunications networks that will allow a sort of sexual simulation, enabling one to reach out and touch other bodies. He imagines the establishment of a telepresence in which representations of bodies can touch and feel one another, moving effortlessly between physical reality and cyberspace, an "interactive tactile telepresence" (Rheingold, 1992, p. 348). For Rheingold, technosex will allow the establishment of intense sexual experiences without the danger of getting pregnant or contracting a sexually transmitted disease. For Rheingold, the sexual encounters that occur through teledildonics occur in cyberspace, a virtual space produced through connected computers, a form of secondary virtual reality that can be entered and exited at will. This is a conceptualization of cybersex closely related to the game space enabled using pods and portals in Cronenberg's eXistenZ.

In a similar vein, Žižek imagines a world where people can outsource sex to younger stand-ins, who will have the responsibility of making love as the older couple shares a quiet drink or conversation (Žižek, 1991, pp. 57-58). Teledildonics incarnate Žižek's fantasies: people who cannot be together use gadgets as stand-ins for sexual organs that deliver to each member of the couple the specific vibrations, tempo, and intensity of the sexual act with their partner. Similarly, Liberati traces a line from cybersex based on textual elements in the early days of the Internet to sex between avatars in virtual worlds like Second Life to the emergence of teledildonics (Liberati, 2017, p. 804). Liberati draws an equivalence between the representation of a body in a virtual world created by the user and the embodied reality of a body that encounters the sex toy. Contemporary teledildonics still require embodiment in the specificity of a body before, during, and after the sexual experience. They function as machines that come into intimate relation with the body and its sexual organs. One cannot do away with the reality of their body; they must be fully embodied to have sex with interactive toys, as the application only enhances the experiences, allowing the vibrations to be mediated.

The contemporary reality of teledildonics differs from disembodied virtual-sex experiences in that it relies much more on bodily corporeality. Unlike chatroom-based cybersex or virtual sex in Second Life, teledildonics allows a mediated interaction of users with sexual machines that imitate different sexual organs. What makes this experience unique, however, is the mediated presence of the partner who is far away, even if that presence can only be implied through the vibrations of their sex toy and video-conferencing software. Teledildonics function as illusory extensions of the human body and its sexuality, allowing long-distance relationships to experience a form of sexual intimacy despite geographical separation. The body is not really extended, but it is allowed through technology to transfer some of its affect and vibrations, but those vibrations are limited to what the technology allows.

Bluetooth sex toys-especially the ones used by couples-do indeed repeat the heterosexual binary logic, but since those are completely new sexual relationships that are emerging between bodies and machines, there is some freedom from the hetero- 
sexual normative canon to be imagined. It is important to remember, however, that we exist in a concrete reality and are still inside the body, a body that experiences affects and vibrations that come from a machine but are imagined to derive from a distant lover, so the ability to have sex with that distant lover remains virtual. Bluetooth sex toys offer a new sexual experience that is neither one of two machines making love to one another nor a substitution of the real sexual experience, but a constellation of sexual organs and machines experiencing intensities that travel by being translated into code through applications.

Each sex-toy company provides a specific application that operates with its products. The applications allow the users to design the tempo, rhythm, and intensity of the vibrations from stronger to lighter, or faster to slower, according to their preferences. Additionally, the applications offer features like video calls and chat, but users often have cybersex while using outside video-conference applications, such as Zoom or Skype. An important mediator that allows those technologies to function wirelessly is Bluetooth technology, which operates using a smartphone and a relevant application. Thus, the first connection required for the intensities to translate from one toy to the other is the one between the sex toy and the user's smartphone or computer via Bluetooth and through the up-todate application of the sex-toy company.

For a successful virtual-sex experience to occur, many elements are required: two connecting sex toys, two smartphones or computers that have installed the most current version of the corresponding company's application, functional Bluetooth signals that allow the toys to stay connected with smartphones, and, finally, a stable wireless connection. To highlight the importance of this often-forgotten connection, I titled this article "Bluetooth orgasms", as the first and most important connection that allows the cybersex to occur is that between the smartphone and the toy. To do away with the cables, a Bluetooth connection with a smartphone and an application connect the toy to the Internet. As the application allows the interactive toy to operate and mediate vibrations, it simultaneously stores information about the body. Each company uses a different application that allows their toys to be controlled and connected, so if you have purchased toys from different companies, you cannot operate them all at once through one app.

Interactive sex toys are also very popular with webcam models, who often masturbate or perform erotic acts online through streaming web broadcasts. The company Lovense provides a unique toolkit for cam shows that can be integrated in many cam sites, allowing many different toys to be connected at once. Through that platform, the performer can connect multiple toys to the platform and have them react to viewer suggestions or allow customers to play interactive games, the results of which are reflected in the vibrations of the sex toys and the body of the performer. In a sense, interactive sex toys have two customer uses: one geared toward long-distance sex between couples and one geared toward sexual performances. The focus of this article is on the former, as it is 
through this mode of coupled sex that a notion of interactive sex between two partners is developed.

While there are multiple options for sex toys, and several designs for Bluetooth sex toys that penetrate the human body, the options for sex toys that are penetrated by the human body are rather limited. The only sex toy offered for such use is a masturbator that functions as an interactive stroker with an air pump and custom-designed masturbation sleeves that can be modified to resemble the feeling of a mouth, vagina, or anus of a specific person or porn star. The most popular non-interactive brand of those masturbators is called Fleshlight: phallic sex toys that imitate the pressure and feeling of a human orifice (an anus, a vagina, or a mouth). The design and marketing of the brand replicate the norm of penetrative interaction.

Faustino describes how teledildonics are introduced as a haptic technology solution that can allow mediated intimacy to solve the problem of long-distance relationships (Faustino, 2018, p. 250). The issue here is that both the design and function of those objects reproduce binary divisions between male and female bodies and between male and female genitalia through the production of paired male and female sex toys (Faustino, 2018, p. 249). It is only fair, though, to acknowledge that both KIROO and Lovense now also offer different pairings that correspond to queer couples. There is still, however, the assumption that a sexual interaction is centered around penetration. In this scenario, genitals are given a privileged position, while the rest of the body is excluded from the sexual interaction and allowed only a visual representation (Faustino, 2018, p. 249). Faustino argues that, through their design, contemporary teledildonics are replicating the "coital imperative" by equating sexual interactions with vaginal penetration by a penis. What Faustino is enabling us to think is that, since remote sex mediated by data and technology is not natural, instead of reinstating the coital imperative, this new sexual interaction can allow for new discoveries.

As human bodies reach orgasm by penetrating and being penetrated by Bluetooth sex toys, the code that has been mediated via Bluetooth is translated into waves of movements and materialized in the technological sex organs through the application. Concurrently, as Bluetooth sex toys penetrate and are penetrated by the human body, they collect data on what sort of vibrations work on the body. Through smartphone applications, one user directs the sexual experience of another. The customization option seems limitless, and one can choose the wave, rhythm, and intensity of the vibration that will be experienced in another body far from one's own. At the same time, the intensity of the vibration must be turned into code in order to move from the controller to the Bluetooth sex toy. A user's preferred vibrations can now be calculated, counted, saved, and stored for future use.

Bluetooth-operated dildos, anal plugs, and strokers all have the capacity to mediate intensities from one human body to another, work together through the application platform provided by the company, and create new sexual synergies among artificial and 
natural organs, Bluetooth signals, vibrations, and code. The body becomes a place where biotechnologies and fabricated extensions meet natural organs. As it vibrates while connected to Bluetooth and Wi-Fi, the body becomes a site that experiences virtual intensities through affective registers.

\section{Bluetooth sex-toy applications in a platform society}

Sexual machines and the applications necessary for their operation - both in their design and in their relationship with the flesh of the body — can be thought of as a metaphor for contemporary capitalist subjectivities, bodies, and sexualities. The interactive sex toys explored here present a solution for a contemporary issue: that of globalization and sexual bodies separated across distances, both too close and too far at once. To defy the distance, the user offers the sexual body's intimate information to the company's applications, which are often marketed as tools that allow a long-distance couple to continue to have intercourse together. Bluetooth-operated sex toys function as sexual organs that masturbate the human body and whose vibrating intensities make bodies orgasm or ejaculate. As the sex toys penetrate the human body, the applications that allow them to operate collect data on what sort of vibrations work for each user's body.

The mediators of this relationship between the two organs are Bluetooth signals and the smartphone application that allows either one partner to command the sexual organ of the other or the two organs to communicate, allowing the two partners a shared experience. Thus, technology offers a solution for a contemporary problem of the human sexual body, but as it solves the issue presented, the technology simultaneously measures and quantifies the body and its tendencies. This intimate relationship among the body, the application, the platform, and the technological organ/sexual machine introduces new sets of questions about intimacy and sexuality, both private and public. What I would like to emphasize is that the body remains at the center of all those relationships, while in its periphery, many questions start to emerge and complicate this central relationship between body and machine via affective registers and data. Just like the bodies of the users function in human societies, the sex toys are designed and manufactured to comply with specific societal norms and rules, and the applications that allow the operation and mediation of those complex sexual experiences are also embedded within a platform society.

Bluetooth sex toys operate within the platform-society ecosystem, as they rely on applications that translate the decisions of one user into vibrations of the machine/organ that vibrates with the body of the other user. According to van Dijck, Poell, and de Waal, platform society is "an emerging society in which social, economic and interpersonal traffic is largely channeled by a global online platform ecosystem that is fueled by data and organized through algorithms" (van Dijck et al., 2018, p. 8). In a sense, the company that generates applications that allow interactive sex toys to operate is a member of this larger 
functioning ecosystem, as intimate personal data move from one device to the next through algorithmic relations. Van Dijck, Poell, and de Waal write that "a platform society is not a given but a dynamically evolving societal arrangement where public values are constantly shaped by different actors" (van Dijck et al., 2018, p. 26). They theorize that, in our contemporary world, we should consider how those online ecosystems-embodied in specific objects and penetrating our everyday reality-can acquire legitimacy through legal and political infrastructures (van Dijck et al., 2018, p. 163). Platforms that function as programmable architectures organizing interactions between users do not simply act as technological tools, but also reveal an internal system for how society is organized and how we live (van Dijck et al., 2018, p. 9). Specifically, the applications required for the interactive use of Bluetooth sex toys complicate ideas about the private and public, the natural and artificial, the biological and technological, and intimacy and consent. It is those complications and the involvement of several human and non-human agents within the sexual experiences that allow us to reconsider what can be defined as a sexual interaction.

Platforms and ecosystems are not beyond ideology and politics, but rather are entrenched with their own ideologies, which often go beyond the legal forces that are reinforced at the state level. So, as we use sexual machines and wireless Bluetooth connections to satisfy our sexual desires and bridge physical distances, we must consider the personal data we scatter across the web and the ideologies that define us as we are penetrated by them. How do those platforms operate seemingly beyond state control, defying borders? Are those Bluetooth sex toys describing a contemporary long-distance love experience while also penetrating the body with the ideological structures of presumed heteronormativity? And how are Bluetooth sex toys and their operation within a platform society redefining what is considered private and public space, and where exactly sexual intimacy stands with respect to those two spaces? Is sexual interaction a perquisite for a healthy body? And how much sex is healthy sex?

Marketed as a sex tool that defies distance for the white heterosexual couple that finds themselves in a long-distance relationship, the ideal pair of Bluetooth sex toys features a masturbator for the male user and, for the female user, a Bluetooth toy that offers clitoral and/or vaginal stimulation and can also be used during penetrative sexual intercourse when the users are united. The introductory video from Lovense (2020) introduces a couple in a long-distance relationship between London and New York; similarly, the video from KIROO presents a relationship between Paris and New York (KIIROO Amsterdam, 2018). The applications provided by the companies operate as connectors that stage the interaction between the distanced users and their toys. They are an integral part of the function of the consumer product and are required for the toys to operate at a distance.

The applications that accompany interactive sex toys function similarly to health platforms and are based on the same idea of wellness. Flore and Pienaar discuss how sexual pleasure is considered a prerequisite for good health, and Viagra and wireless sex 
toys become aids to achieving this idea of sexual wellness (Flore \& Pienaar, 2020, p. 280). Teledildonics function as sensory objects that collect sexual data, improve sexual experiences, and ensure that the coital act will occur even via extensions of the human body with the aid of haptic sexual machines and communication technologies. Flore and Pienaar argue that data become the lubricant for long-distance intimacy and central actors in the (re)making of sexual subjectivities, intimacies, and "healthy" sexuality (Flore \& Pienaar, 2020, p. 281). Bodies become senders and receivers of vibrations mediated by the applications. The application that allows the toys to operate becomes an interface that mediates the relationship between the sex toy and body of one lover and those of the other lover.

Under the justification of customer support and quality improvement, the companies collect anonymous information, like which of the app's features are used, the vibration modes, screens viewed, and time spent on the app. Whether attached to a specific name or not, intimate details about anonymous bodies are collected, defining a new sexual norm. Flore and Pienaar define this process as a datafication of sex: "a process by which intimate desires and practices are coded as data packets that can travel long distances to a partner" (Flore \& Pienaar, 2020, p. 286). The applications developed to aid the functioning of Bluetooth sex toys are closely related to health applications and function in a similar manner of exchange. The KIROO application Feel Connect 3.0 allows the user to connect to content or a partner after syncing the sex toy to the application through Bluetooth, thereby allowing them to "make love from anywhere in the world". The application provided for the Lovense sex toys Nora and Max advertises the security of their platform, emphasizing that it encrypts data-especially texts, pictures, and voice messages. It does, however, record the vibration patterns used during the call and allows them to be replayed later. Since the function of those applications is dual, functioning partially as a connector between the toys and partially as a regular messaging, video-call application, the data that pass through the companies' servers are also data of two types: the vibrations, tendencies, and habits of the sex toy's operation, as well as the personal interactions via the messaging features of the users. This data collection is presented as necessary for the improvement of the products and the creation of an optimal experience for customers.

Similar to health apps, the teledildonic application creates an interplay between private gain and public good. The two-sided logic behind the platform-based economics of health and fitness apps serves as personalized data-driven services for their customers, while also serving the public interest of medical research, according to van Dijck and Poell (2016, p. 1). It is this exchange of personal data for personalized solutions that lurks behind those exchanges of data for vibration fostered in teledildonic apps. The consumer simultaneously becomes both a data subject and a research subject (van Dijck \& Poell, 2016, p. 8). When using app-enabled sex toys, however, the users are often unconsciously contributing intimate personal information and data to these toys' manufacturers. Sex, orgasms, and vibrations become quantifiable, measured, and stored information that transform the sexual subject into a data subject and a research subject-this time for research on 
sexual wellness. The personal information of the waves of affect that move between the bodies and sex toys of the users is offered in exchange for a virtual sexual experience that can defy distance. This unconscious submission of data exchanged for long-distance intimacy becomes another form of control.

Bluetooth sex toys are marketed as a fun, interesting way to defy physical distance and allow interactive virtual sexual experiences, but many security and data concerns are involved in those exchanges between orgasms and vibrations. Data collection through the apps is not the only issue with data; there are also data breaches, data leaks, and bugs that lead to further complications and sometimes even sexual assault. An example of an issue raised about using Bluetooth sex toys was the 2017 legal suit against We-Vibe regarding a data breach related to its We-Vibe 4 Plus sex toy. Since the application had many security and privacy vulnerabilities, anyone within Bluetooth range could apparently take control of the device. As a result, the company was ordered to pay customers who had purchased its product.

In a sense, the body becomes leaky, leaving data and information behind it as it encounters sensory sex toys. Wilson-Barnao and Collie examine the transformation of the vibrator into a sensory object that enables and normalizes the syncing of everyday activities with the cloud, transforming patterns of sexual activity into a leakier experience that is visible, hackable, and searchable (Wilson-Barnao \& Collie, 2018, p. 738). Data extracted from the body are beneficial to the consumer experience, as they help the company improve its products. Bluetooth sex toys rely on the capacity of mobile digital devices that, once connected to platforms, can dramatically extend the senses by incorporating haptic technologies with digital networks to enable a radical extension of the sense of touch (Wilson-Barnao \& Collie, 2018, p. 740). By comparing Bluetooth sex toys to drones and the sense of touch to the sense of vision, they create the term the droning of intimacy. They write:

\footnotetext{
This droning of intimacy produces increasingly leaky bodies subject to datafication and algorithmic processes - "drained" by the affordances specific to digital technology driven by capitalist imperatives. Further, these entanglements in turn alter the nature of intimacy and the private experience of the body. (Wilson-Barnao \& Collie, 2018, p. 741)
}

When dealing with such intimate experiences and information, those applications' power over and obligations toward their customers are enormous. More than just a change in intimacy and a need to regulate the use of such sex toys for the safety of consumers, a new discussion has begun about how those sexual experiences are opened to a new type of public, the public of the platform society. Although some data, like the personal conversations of users during their sexual encounters, are protected, the information extracted from the leaky body as it orgasms and interacts with non-human sexual organs belongs to the manufacturing companies. 
In "Postscripts of the Societies of Control", Deleuze (1992) foresees the transformation of the individual into a dividual, and the move from a disciplinary society into a society of control. He sees a transformation from Foucault's regimes of discipline, which focus on biopower, like the prison, the hospital, the school, and sexuality, into an internalization of this discipline. Influenced by cultural theorist and philosopher Paul Virilio, Deleuze describes a "free-floating control that replaces the old disciplines operating in the time frame of a closed system" (Deleuze, 1992, p. 4). Discipline is internalized, and computers and machines contribute to the process of closely monitoring and calculating the body and its movements and modulations (e.g., steps, calories): "the numerical language of control is made of codes that mark access to information or reject it" (Deleuze, 1992, p. 5). From the waves that make the body orgasm to the steps counted in an application like Google Fit, the hours slept, the calories consumed, the body becomes a quantifiable entity that is closely measured and counted as it moves through its private everyday life. Technologies like the Bluetooth sex toys enter into a closer and closer relationship with the body, extracting desires and information. Working in synergy with other applications and technologies, like smart watches, the monitoring process becomes more and more holistic.

In a sense, Bluetooth sex toys are an integral element of the societies of control, as the sex toys become sensory objects that track and trace what makes different bodies orgasm. What was once thought of as the most private information is now translated into code and exposed to a new sort of public. What was once the closest form of connection - a feeling reliant on touch, closeness, and intimacy-has now become an intimate entanglement with technological organs. Those shifts alter how we perceive not only sexual encounters but also the notions of private, public, personal, and shared. Sundén takes a materialist approach to examining the data breaches and data leaks in teledildonics to discuss intimacy and privacy within the digital networks of human and non-human actors. How can we achieve sexual intimacy and remain exposed yet safe on public digital networks? Network connectivity allows play between partners at a distance and new forms of sexual play, but at the same time,

bodies and devices are opened up to hacking and leaking, as bodies made data came to circulate through applications and networks that may be everything but safe. When sexual play becomes data, safe sex becomes a matter of keeping ones' data safe. (Sundén, 2020, p. 2).

Sundén argues for the need to de-link intimacy from privacy and for users to accept that networked sexual play is a highly intimate and personal experience, but hardly private. Users deserve, however, to be safe and to have their data kept safe and processed safely (Sundén, 2020, p. 12), even if they decide to have sex in the public space of the Internet.

Penetrative machines and artificial sexual organs have existed for centuries, but what is new here is that those machines can mediate intensities from one human body to another, work in unity, and create new sexual synergies among Bluetooth signals, vibra- 
tions, code, and artificial and natural organs, while also exposing the body to a new form of the public. In Countersexual Manifesto, Preciado introduces the dildo as a technology and a prosthetic capable of liberating humanity from structures of gender and sexuality. Preciado views the dildo as an artificial phallus, which is also a technology, an organ that does not feel but produces orgasms, an extension of the human body that has the potential to reverse gender norms in sexual acts. In a sense, everyone has an anus, hands, fists, fingers, or feet that can function as dildos, and this changes and destabilizes what we think of as natural sex (Preciado, 2018, p. 42). In a sense, there is no natural and artificial sex as we might conceive it. There has never been natural sex. New technologies allow for new sexual organs - both human and non-human - vibrations, codes, and data to become entangled in a sexual encounter that might seem concealed but is also public.

Similar to Preciado's dildo, interactive sex toys do not entail within them the disappointment of the penis; they are always there, always hard, always charged, always ready to vibrate and please. The only prerequisite is that they manage to connect via Bluetooth to the application that allows them to operate and be controlled by another. Preciado's dildo differs from the phallus because the phallus is imaginary, and the dildo is real technology, a real prosthesis. What happens when, according to Preciado's revolutionary ideas about technology, sex toys, and the disruption of gender and sexuality norms, we add to the online mix of applications, software, and Bluetooth technologies? Preciado thinks of the body and sexuality as being already infused with and impossible to separate from technology; in other words, every technological "organ" reinvents a "new natural condition" by which we are simultaneously disabled and enabled (Preciado, 2018, p. 136).

Bluetooth-operated sex toys lie at the intersection of organ and machine. For Preciado (2018), we are all cyborgs in a way, our bodies constantly merging with new technologies and allowing us to experience new ways of being. In Nomadic Subjects, Braidotti looks at how biotechnologies have allowed the separation of bodies and sex from reproduction. Biotechnology has allowed us to have sex without babies (e.g., the birth control pill) and babies without sex (e.g., IVF; Braidotti, 1994, pp. 181-182). Interactive sex toys present a new way of having sex without the requirement of two bodies being present in an intimate embrace-a new type of sex where the body is leaky, spreading data into the cloud as it orgasms without requiring another body.

Bluetooth-operated sex toys are biotechnologies that are infused with code and algorithms and create affective sexual relationships with the human body. The body is a site for the experience of intensities through affective registers. It is much more than its organs and actual reality, and lately, it has increasingly become a place where biotechnologies and fabricated extensions meet natural organs. While extracting data from the sexual body about its tendencies and sexual bodily preferences, biotechnologies allow gender, sexuality, intercourse, and intimacy to be reconsidered. 


\section{Conclusion}

This article argues for the need to consider intimate encounters between interactive sex toys and bodies as complex technological and biological assemblages where vibrating machines and the flesh of the human body come into intimate connection through the inevitable process of datafication. Like any technology or object, interactive sex toys carry within them the heteronormative societal ideologies and norms of the societies that produce them and are still susceptible to technological limitations. The original intention is for those sexual machines to function as they are marketed: as a substitute for the real heteronormative sexual encounter, strengthening the notion of the coital imperative. Those entanglements between vulnerable, naked human bodies and sexual machines, however, create a completely new reality and a new form of sexual encounter that does not really resemble "real sex" but comes close to a simulated experience of mutual masturbation.

The virtual and the digital, data and algorithms, and applications and platforms are not entrenched in invisibility floating in space, untouchable and unconscious, accessible only through the screens of laptops and smartphones. Virtuality is incarnated in real objects that are designed to exist in the real world that we all share and experience through the body. The Bluetooth sex toys presented here penetrate bodies with their form while also being entrenched in ideology, data, and code. The information extracted by the human body is gathered by the application and shared with the marketing team who provides the service. Concurrently, algorithms and codes are written by people with specific purposes in mind.

Bluetooth sex toys function as sexual organs without bodies. Their silicone form can be transformed into anuses, vaginas, phalluses, and other mysterious organs that offer pleasure without resembling human body parts. They penetrate and are penetrated by the body, vibrating to a coded rhythm determined and enacted through the application. They operate with the aid of digital sequences of code, but their waves or vibration are experienced by the analogue sensuous body.

It is important to emphasize that software, machines, and bio-fabricated organs are all objects that are human technologies and structures and affect, in a variety of ways, the production of subjectivity. Similar to technology, race and gender are also human structures and technologies that form different subjects. Is there, then, any hidden potentiality within those new ways of having sex, a sex executed between human and non-human factors for the abolition of the structures that no longer serve, or will we continue mindlessly feeding applications and machines with more and more of our data to allow them to improve their products? Is there a way to see things differently and manipulate technology for the emergence of a new regime?

Design objects and technologies arise as solutions to problems of everyday reality. At the same time, however, design objects operate in a specific manner encapsulating society's inherent conditioning and often reiterating preconceived assumptions and ideas. 
Synergies between the body and technology produce affects, circulate intensities, and interfere with embodiment and the everyday experience.

In Queer OS, Keeling considers software, technology, and operating systems in relation to the technologies of race and gender, sketching "a project at the interfaces of queer theory, new media studies, and technology studies" (Keeling, 2014, p. 153). Keeling imagines the possibility of the creation of queer as an operating system that might be able to produce or break down common sense. In this article, I have tried to find a way to read those intimate relationships between technology and the body and make visible those invisible and commonsensical norms that lay behind them. Removed from fields of imagination and the software cloud, as they penetrate the human body, perhaps digital virtualities and sexual machines can allow us to explore new types of erotic assemblages between humans and non-humans and strive for negotiations among sexuality norms, both private and public.

\section{Acknowledgments}

I would like to thank the UCSC SSRC-DPD Program and the Humanities Institute at UC Santa Cruz for providing the support to develop this project. I would also like to thank Anna Friz for providing the space in her course to develop the first fragments of this idea as well as my cohort in the department of Film and Digital Media: Sarah Bird, Ksenia Fir, Lalu Esra Ozban, Amy Reid and Kelly Sky.

\section{References}

Ahmed, S. (2014). The cultural politics of emotion (2nd ed.). Edinburgh University Press.

http://pratiquesdhospitalite.com/wp-content/uploads/2019/03/245435211-sara-ahmed-the-culturalpolitics-of-emotion.pdf

Braidotti, R. (1994). Nomadic subjects. Columbia University Press.

Cronenberg, D. (Director). (1999). eXistenZ [Film]. Canadian Television Fund; Dimension Films; Harold Greenberg Fund; The Movie Network; Natural Nylon; Telefilm Canada; Serendipity Point Films; UGC. de Lauretis, T. (2008). Becoming inorganic: Cronenberg's eXistenZ, virtuality and the death drive. In T. de Lauretis (Ed.), Freud's drive: Psychoanalysis, literature and film (pp. 88-114). Palgrave Macmillan. https://doi.org/10.1057/9780230583047

Deleuze, G. (1992). Postscript on the societies of control. October, 59, 3-7. https://www.jstor.org/stable/778828

Faustino, M. J. (2018). Rebooting an old script by new means: Teledildonics-the technological return to the "coital imperative." Sexuality \& Culture, 22(1), 243-257. https://doi.org/10.1007/s12119-017-9463-5

Flore, J., \& Pienaar, K. (2020). Data-driven intimacy: Emerging technologies in the (re)making of sexual subjects and "healthy" sexuality. Health Sociology Review, 29(3), 279-293.

https://doi.org/10.1080/14461242.2020.1803101

Keeling, K. (2014). Queer OS. Cinema Journal, 53(2), 152-157. https://doi.org/10.1353/cj.2014.0004 
KIIROO Amsterdam. (2018, December 18). KIIROO helps you close the gap-Ultimate LDR couples toys [Video]. YouTube. https://www.youtube.com/watch?v=u1GLaaPZLMo

Liberati, N. (2017). Teledildonics and new ways of "being in touch": A phenomenological analysis of the use of haptic devices for intimate relations. Science and Engineering Ethics, 23(3), 801-823.

https://doi.org/10.1007/s11948-016-9827-5

Lovense. (2020, December 1). Long-distance interactivity [Video]. Vimeo. https://vimeo.com/485877385

Massumi, B. (2002). Parables for the virtual: Movement, affect, sensation (1st ed.). Duke University Press.

Pellegrini, A., \& Puar, J. (2009). Affect. Social Text, 27(3 (100)), 35-38.

https://doi.org/10.1215/01642472-2009-004

Preciado, P. B. (2018). Countersexual manifesto. Columbia University Press.

Rheingold, H. (1992). Virtual reality: The revolutionary technology of computer-generated artificial worldsand how it promises to transform society. Simon \& Schuster.

Shields, R. (2002). The virtual (1st ed.). Routledge. https://doi.org/10.4324/9780203987186

Sparrow, R., \& Karas, L. (2020). Teledildonics and rape by deception. Law, Innovation \& Technology, 12(1), 175-204. https://doi.org/10.1080/17579961.2020.1727097

Sundén, J. (2020). Play, secrecy and consent: Theorizing privacy breaches and sensitive data in the world of networked sex toys. Sexualities. Advance online publication. https://doi.org/10.1177/1363460720957578

van Dijck, J., \& Poell, T. (2016). Understanding the promises and premises of online health platforms. Big Data \& Society, 3(1), 1-11. https://doi.org/10.1177/2053951716654173

van Dijck, J., Poell, T., \& de Waal, M. (2018). The platform society. Oxford University Press. https://doi.org/10.1093/oso/9780190889760.001.0001

Wilson-Barnao, C., \& Collie, N. (2018). The droning of intimacy: Bodies, data, and sensory devices. Continuum, 32(6), 733-744. https://doi.org/10.1080/10304312.2018.1525922

Žižek, S. (1991). Looking awry: An introduction to Jacques Lacan through popular culture. MIT Press.

Marilia Kaisar

PhD Student

Department of Film and Digital Media

University of California Santa Cruz

mkaisar@ucsc.edu 